Available online at www.banglajol.info

Bangladesh J. Sci. Ind. Res. 48(3), 205-212, 2013

Short Communication
BANGLADESH JOURNAL OF SCIENTIFIC AND INDUSTRIAL RESEARCH

E-mail: bjsir07@gmail.com

\title{
Development of electroplating process for plating polyamides
}

\author{
M. V. Kulkarni ${ }^{1}$, K. Elangovan ${ }^{2}$ and K. H. Reddy ${ }^{1}$ \\ ${ }^{1}$ Department of Mechanical Engineering, JNTU College of Engineering, Anantapur-515002, Andhra Pradesh, \\ India \\ ${ }^{2}$ Department of Mechanical Engineering, Cambridge Institute of Technology, Bangalore-560036, Karnataka,
}

\begin{abstract}
We report a method of converting non-conductive plastic surfaces into conductive by coating with copper based conductive paints onto polyamide6 (Nylon6) plastics to create a conducting surface for a subsequent copper deposition and thus for electroplating them. Nylon6 are basically hygroscopic materials and difficult to plate and hence conductive painting procedure has been adopted for electroplating them. The electroless plating procedure that is normally followed in plating of plastics has been avoided and thus a new method of plating on plastics has been presented in this research paper.
\end{abstract}

Keywords: Electroplating; Conductive paints; Nickel coating; Nylon6; ABS; PA6

\section{Introduction}

For many years, rapid advances in resin development and production technology have resulted in the replacement of metals by plastics in a wide range of applications. Advantages of plastics are ease of fabrication, one stage moulding of parts, greater design flexibility and weight savings. Although decorative finishes can be obtained on plastics by moulding in colour or painting finished parts, a reliable method was required for producing the high quality, bright reflective surfaces that were available on metallic substrates by nickel/chromium plating. Aesthetically, bright finishes have well-established and popular appeal and also offer important functional advantages, such as their wear resistance and hygienic properties. It was the need to produce bright finishes on plastic substrates that led to the development of the processes used so successfully today (Hart, 1995).

Electroplating is the process of coating a metallic or other conducting surface with a thin layer of metal by electrolysis (ASTM, 2003). The core part of the electroplating process is the electrolytic cell. In the electrolytic cell a current is passed through a bath containing electrolyte, the anode, and the cathode (Helen Lou, 2006). The work piece to be plated is the cathode (negative terminal). The anode, however, can be one of the two types: sacrificial anode (dissolvable anode) and permanent anode (inert anode) (Kanani, 2004).

Electroplating products are widely used for many industries, such as automobile, ship, aerospace, machinery, electronics, jewelry, defense, and toy industries. Electroplating on plastics can be carried out by two methods, the first method is called electroless method in which the surface of the plastic is roughened to allow metal to adhere, and then electroplate over that layer to build up layers of metal. This process is also known as auto-catalytic or chemical plating method. The second method is to apply conductive paint to the plastic, then electroplate it (Dohrman)

Conductive paints have traditionally been used to coat plastics to achieve EMI shielding. This technology is based on the incorporation of a conductive filler and pigments into a resin binder. In general, the alternative types of conductive fillers used in today's conductive paints include copper, silver, graphite or nickel. The primary binder systems used in the formulation of these products include vinyl's, acrylics, polyurethanes and epoxies. The most commercially signifi-

*Corresponding author. e-mail: kulkarni.mithun@hotmail.com 
cant conductive paint technology today is based upon copper. Conductive paints have made major advancements in both coating formulations and in the production equipment used to apply them. Today, paint technology offers great versatility to product designers, applicators, and specifiers by optimizing economy while achieving a quality result for a wide range of part designs (Roy Bjorlin, 2004). Hence, in this paper a method of plating on polyamide plastics using conductive paints has been discussed.

\section{Background of electroplating of ABS plastics}

Plating of plastics was originally developed using ABS (Acrylonitrile Butadiene Styrene), although other materials have been used in more specialist applications where the properties of ABS are too limited (Parkinson, 1994). Normally electroplating on ABS plastics involves the steps as shown in Fig. 1. The etching process involves burning of butadiene particles from ABS sample creating microscopic holes in the sample. These microscopic holes act as the site for the deposition of electro platable materials. The etched samples are then activated through an activation process which is also known as catalyzing process in which a catalytic film is deposited on the surface of the etched samples to prepare the sample for electroless metal plating. The activated sample is then given a thin coat of either nickel or copper using electroless solution; this completely prepares the sample for further electroplating the samples using the conventional route for electroplating metals. The electroplating involves dipping the electroless samples in acid copper solution and then giving a coat of nickel and finally coating with Chrome.

\section{Objective}

The main objective of this research work is to show that polyamides can also be electroplated. It is generally known that polyamides can be plated but with great difficulty, and hence we have made an attempt to simplify the plating on polyamides by avoiding the electroless procedure, and adopting a new and a simple procedure (conductive painting) which could be economical (Fig. 2).

\section{Materials and methods}

\section{Sample preparation}

The polyamide specimens were fabricated as per ASTM standards using the injection molding technique (Fig. 3). The prepared samples were to be subjected to various mechanical tests like tensile, compression, hardness, flexural and wear studies in dry state, water absorbed state and in electroplated state from the stand point view of strength and wear but the method of electroplating polyamide samples has only been discussed in this paper.

Two types of samples namely scoured and unscoured samples were used in the study. Adhesion evaluation test was conducted on scoured and unscoured samples. The scoured samples were prepared by scouring the samples (Fig. 4) with 300 -grit sandpaper (scouring creates a rough surface for the conductive paint to adhere), rinsed with tap water, and

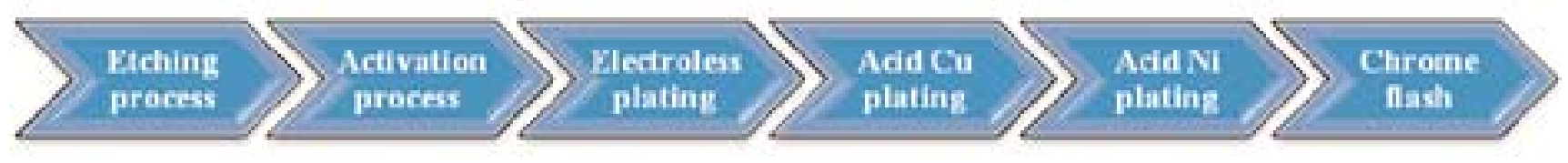

Fig. 1. Electroplating procedure on ABS plastics

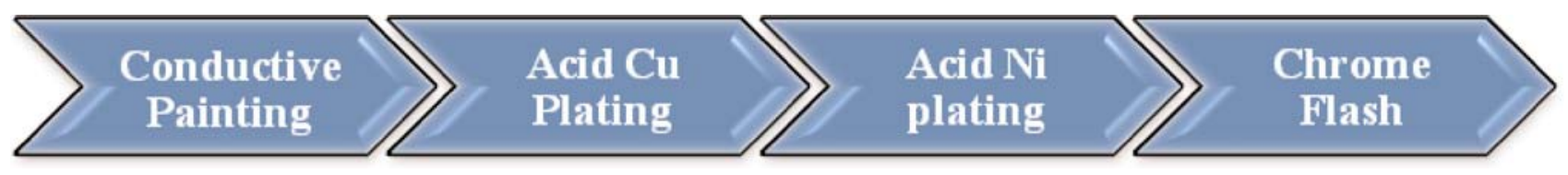

Fig. 2. Electroplating procedure adopted for plating on Nylon6 / PA6 samples 


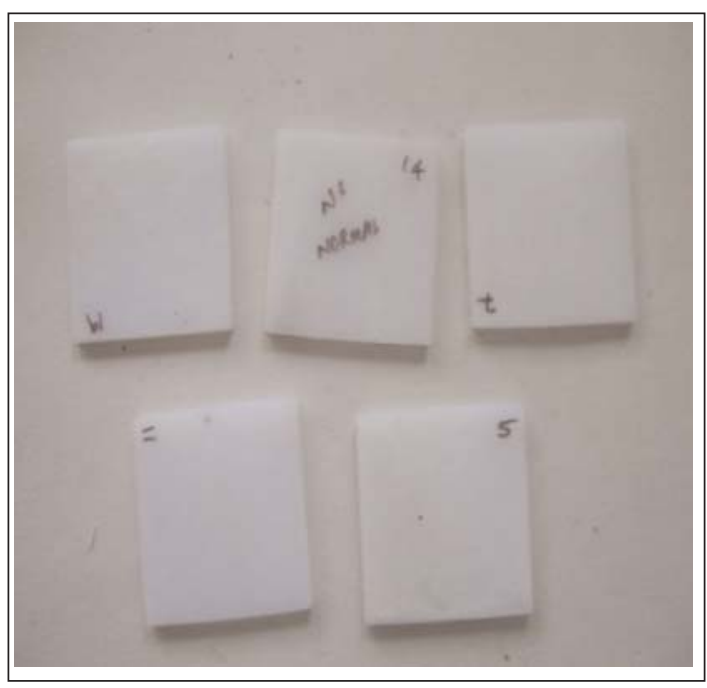

Fig. 3. Samples before painting

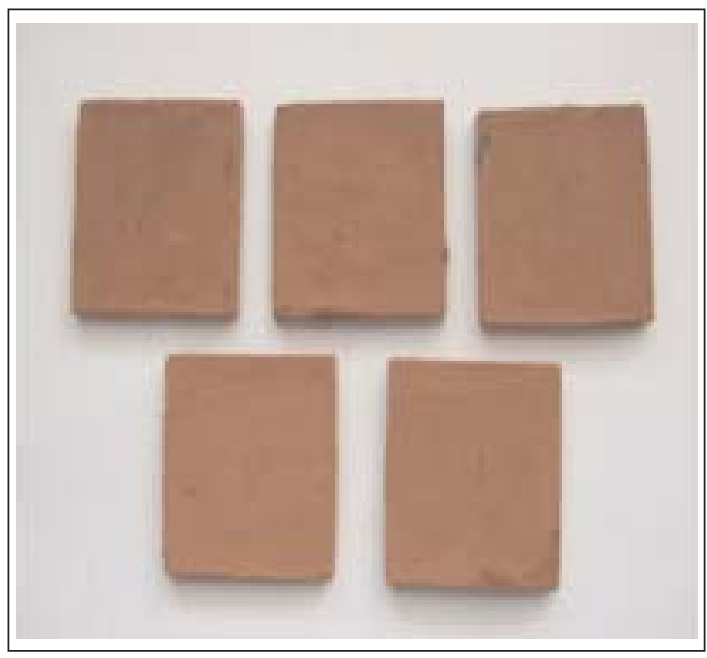

Fig. 5. Scoured samples after painting

dried in an oven pre-heated to $40^{\circ} \mathrm{C}$ for $30 \mathrm{~min}$. The scoured PA6 samples were then coated with copper based conductive paint (Fig. 5), and left for sun drying for a period of $4 \mathrm{hrs}$ to achieve conductivity. A digital multimeter was used to measure the resistance of the painted samples (Fig. 6).

\section{Electroplating procedure}

The Conductive painted specimens / samples were subjected to the processes as mentioned in the Figure 2 which

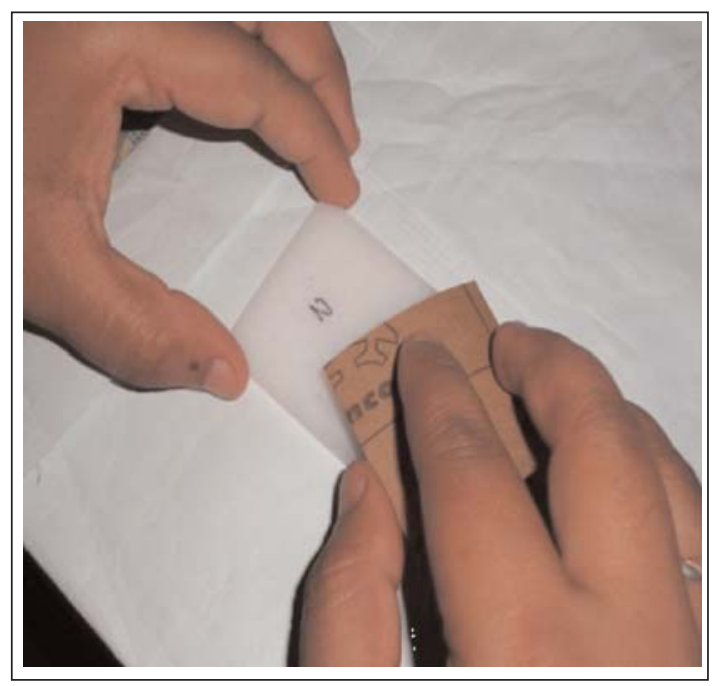

Fig. 4. Scouring of samples with sand paper

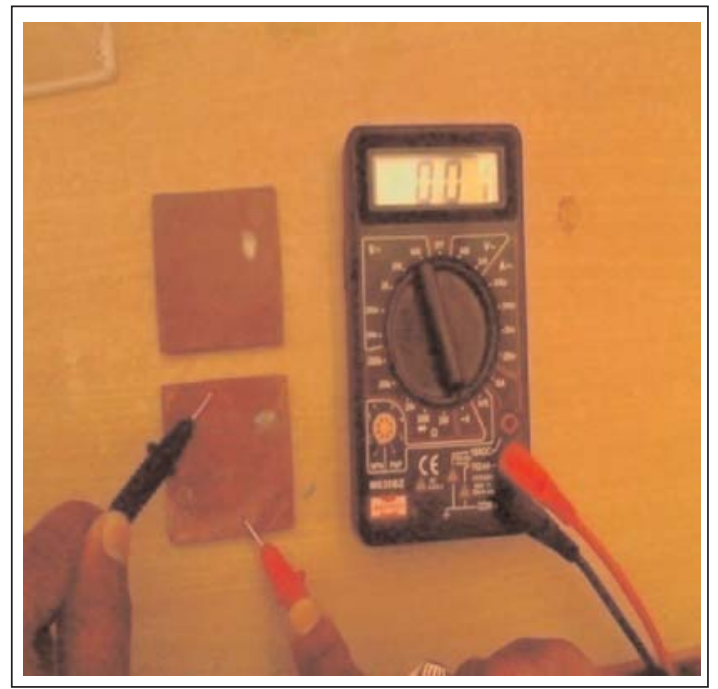

Fig. 6. Conductivity measurement using digital multimeter

involves acid copper plating followed by acid nickel plating and finally chrome flash.

\section{Acid copper plating}

Acid copper plating is referred to as actual plating process / copper electroplating. The solution for acid copper plating is prepared by mixing $200 \mathrm{gm} /$ litre of copper sulphate and $30 \mathrm{ml} /$ litre of sulphuric acid to DM (demineralised) water. The solution prepared is left for 10-15 minutes to attain uni 


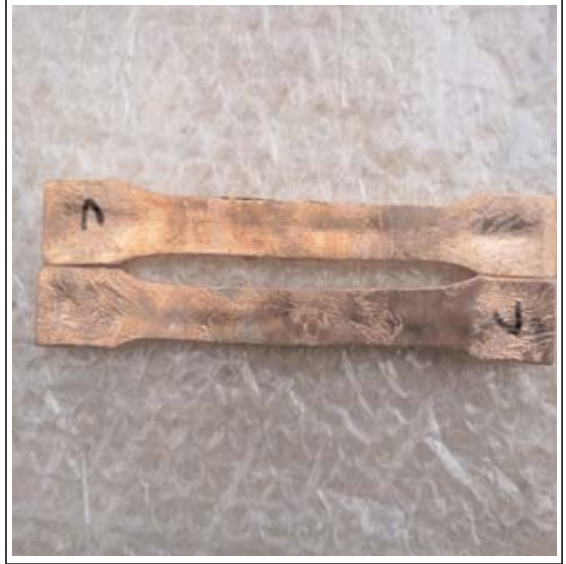

Fig. 7a. Acid copper plating tub with solution

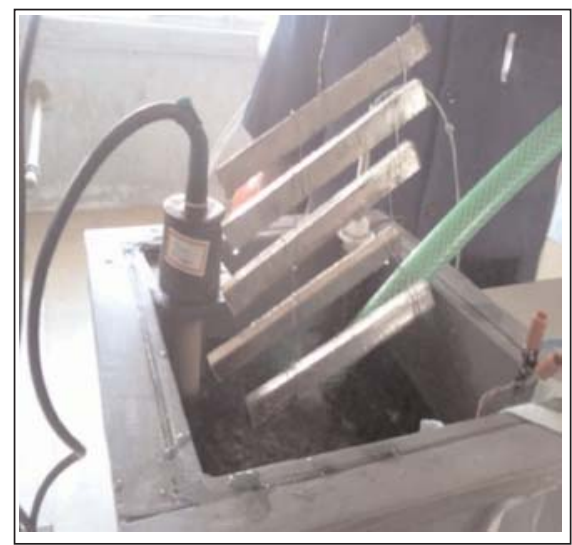

Fig. 8a. Nickel plating tub with solution (nickel plated flexure specimen also visible)

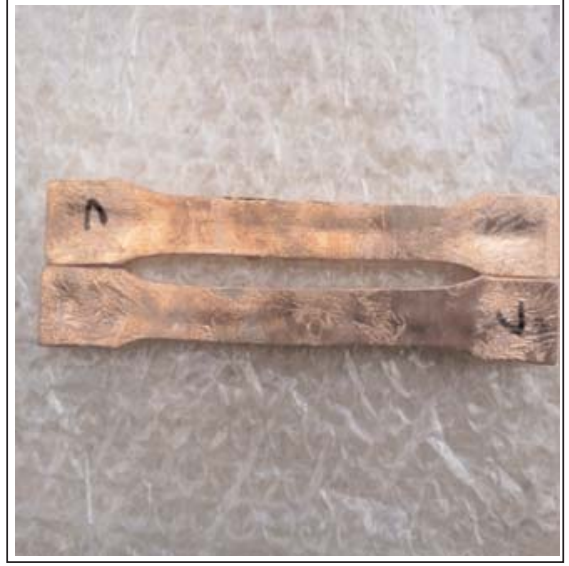

Fig. 7b. Copper plated tensile specimens

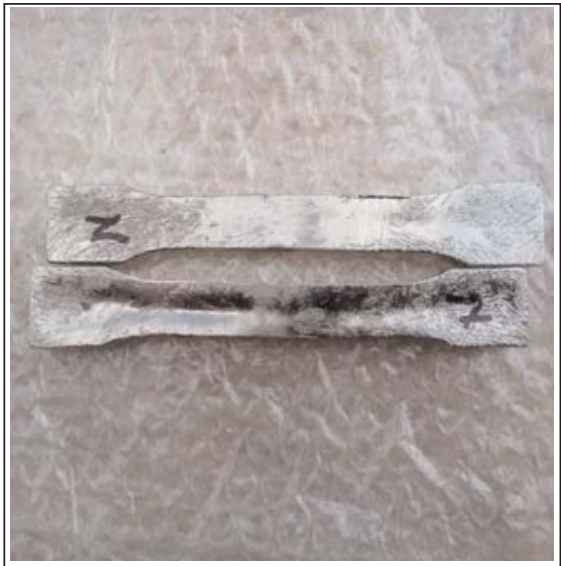

Fig. 8b. Nickel plated tensile specimens

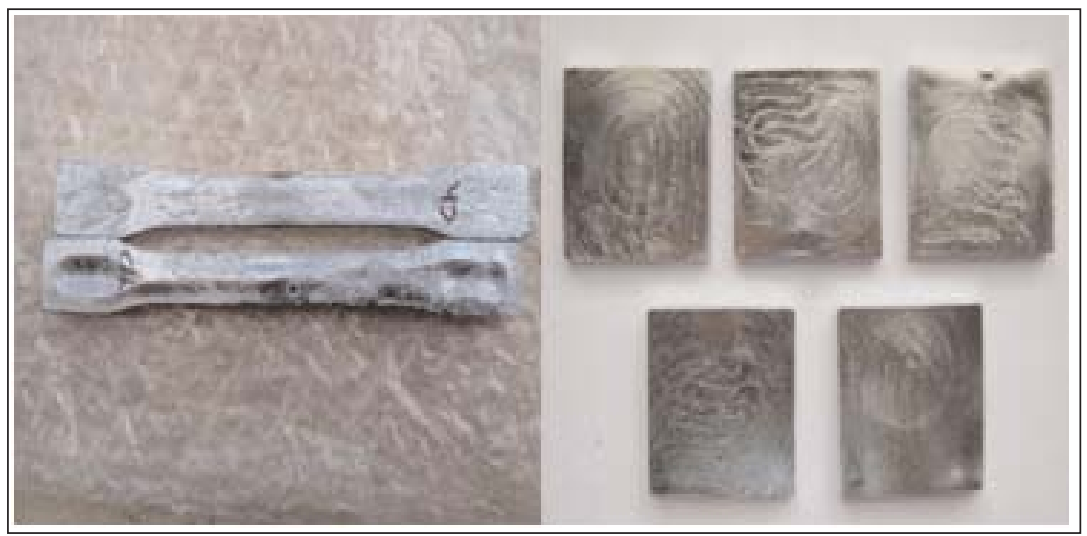

Fig. 9. Chrome flashed tensile and hardness samples 
formity. Brightener (coumarin) and leveller (sodium allyl sulphonate) solution are also added to the prepared solution. The copper anode is immersed in the tub containing the solution (Fig. 7a). A current density of $20-50 \mathrm{~mA} \mathrm{~cm}{ }^{-2}$ was applied and the operating temperature maintained was around $20-40^{\circ} \mathrm{C}$. The current efficiency was between $95-$ $99 \%$. The conductive painted specimens were then dipped in the prepared solution (Fig. 5) for about 10-15 minutes or till the plating was complete. The electroplated specimens were then rinsed in $30 \% \mathrm{HCl}$ solution to remove any excess material, and also to obtain a uniform surface finish on the specimen. The specimens were then rinsed in DM water to remove the remaining $\mathrm{HCl}$ solution.

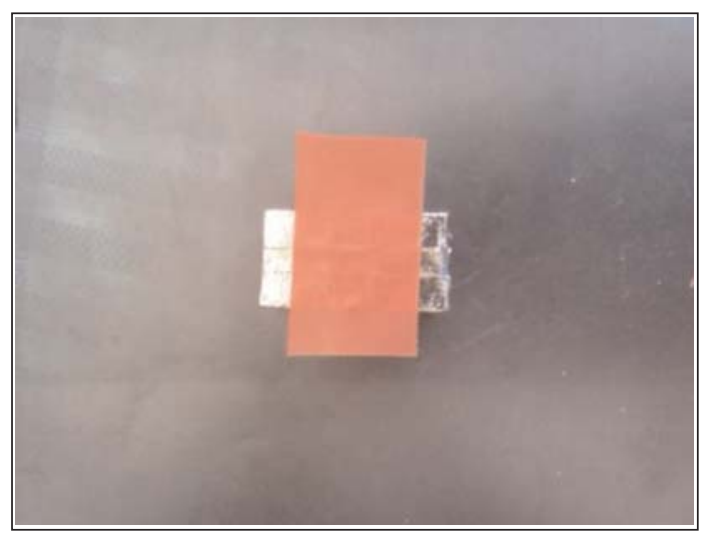

Electroplated compression sample

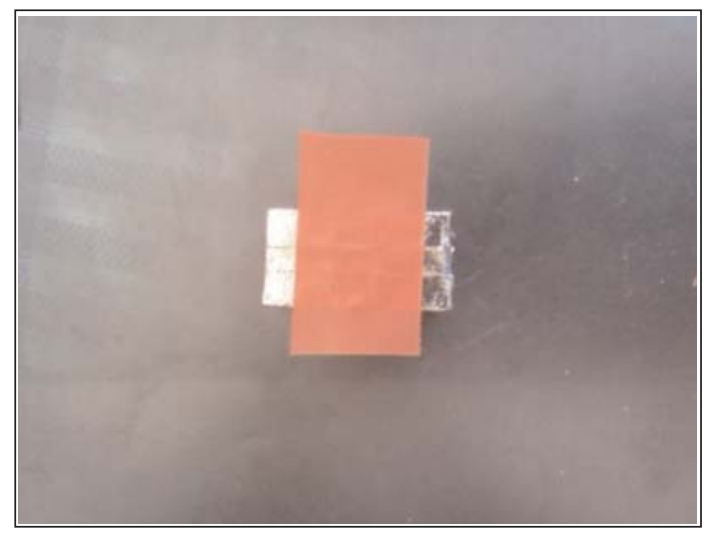

Fig. 10. Adhering tape

\section{Nickel plating}

As in copper electroplating process copper is plated, in the same manner, a metallic coat of nickel is deposited, nickel electro plating is carried upon the copper plating which will increase the plating strength and also protects the copper layer for oxidation. The nickel solution was prepared by mixing the nickel salt $(350-400 \mathrm{gm} / \mathrm{L})$ in $\mathrm{DM}$ water. The operating temperature of the solution was maintained at around $40-50^{\circ} \mathrm{C}$ for the nickel plating to take place; the nickel anode was placed in the tub containing the solution (Fig. 8a). A current density of $20-50 \mathrm{~mA} \mathrm{~cm}^{-2}$ was applied. The current efficiency was around $95 \%$. The specimens were then dipped in nickel plating bath solution for about 5 minutes. The plated specimens were then rinsed with $30 \% \mathrm{HCl}$ solution and then with $\mathrm{DM}$ water to remove the excess $\mathrm{HCl}$ solution.

\section{Bright chrome plating}

A thin layer of chrome plating is deposited on the nickel surface. Chromium plating provides excellent hardness, bright appearance with no discoloration, and resistance to corrosive environments. The solution for chrome plating is prepared using chrome salt (250 gm /L) mixed with sulphuric acid (1 $\mathrm{mL} / \mathrm{L}$ ). The solution prepared was maintained around the temperature of $45-50^{\circ} \mathrm{C}$. The holding time of the specimens will be around 30 seconds (Fig. 9). A pH 3.5 - 4.5 has to be maintained for the chrome plating. The type of anode used has a composition of $(1.5 \%$ antimony $+91.5 \%$ lead $+7 \%$ tin $)$ anode. The current density used for the plating was $1.5-2$ amp/square inch.

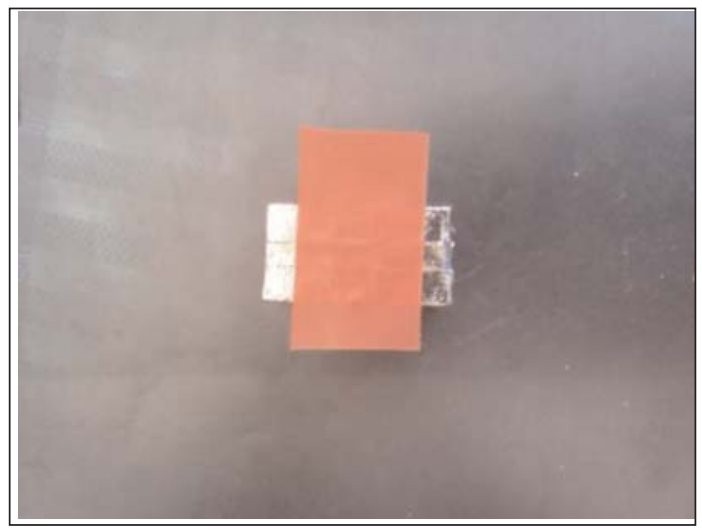

Fig. 11. Cross marked sample 


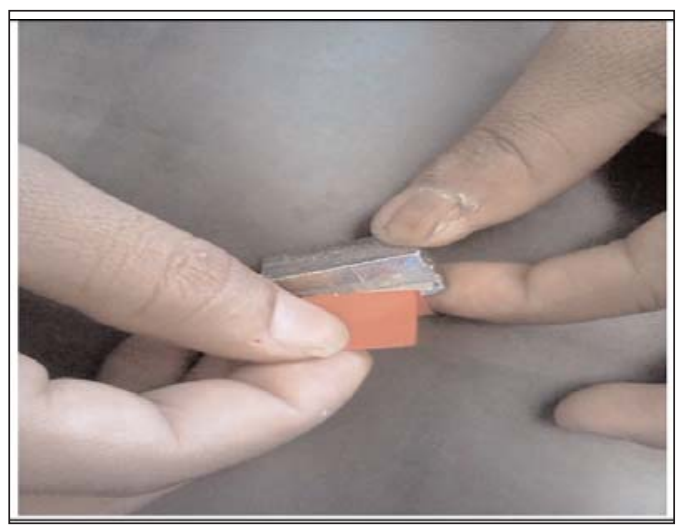

Fig. 12. Tape being pulled off

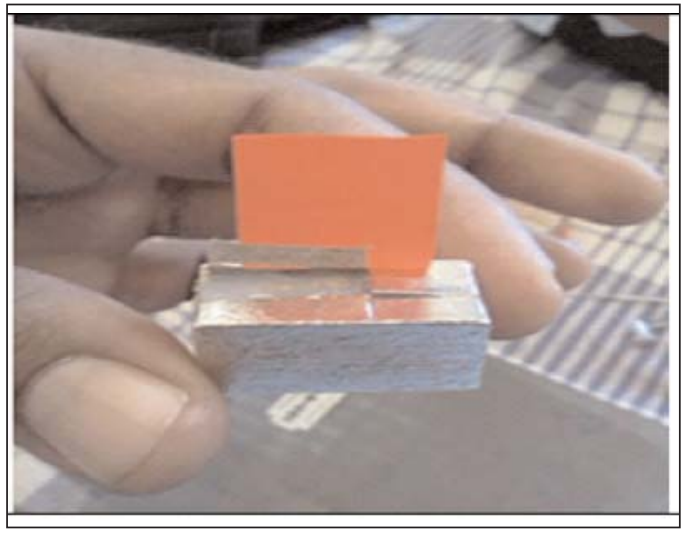

Fig. 13. Peeled off layer

\section{Adhesion evaluation}

The adhesion of $\mathrm{Cu}$ paint to the scoured and unscoured polyamide surface and that of the electroplated deposits to the painted surfaces were evaluated using a simple tape test (Fig. 10). Cross marks were cut using a blade on the electroplated polyamide surface (Fig. 11), and a tape was made to adhere on to the surface of the cross marks, the tape was pulled off (Fig. 12). It was found that the electroplated layer had come off the surface due to the smooth surface of the unscoured polyamides samples (Fig. 13). At the same time peeling was not observed in scoured PA6 samples.

\section{Results and discussion}

The electroplating of polyamides was governed by certain parameters like chemical concentration, current density, temperature, oxidation and pollution of electrolyte (Fig. 14). It is to be noted that any slight variation in chemical concentration and current density would lead to improper plating or uneven plating. Excessive current density also caused plated material to burn out; this also increased the temperature of the electrolyte. Although the operating temperature range in a nickel bath can be quite wide, (from 54 to $76^{\circ} \mathrm{C}$ ), the most recommended temperature is between 60 and $70^{\circ} \mathrm{C}$ (Baudrand, 1994). But the temperature increased drastically to $85^{\circ} \mathrm{C}$, when there was a change in current density from 20 $\mathrm{mA} \mathrm{cm}{ }^{-2}$ to $30 \mathrm{~mA} \mathrm{~cm}^{-2}$. It was also seen that due to this excessive temperature of the nickel electrolyte, peeling of the previous copper layer was observed (Fig. 14).
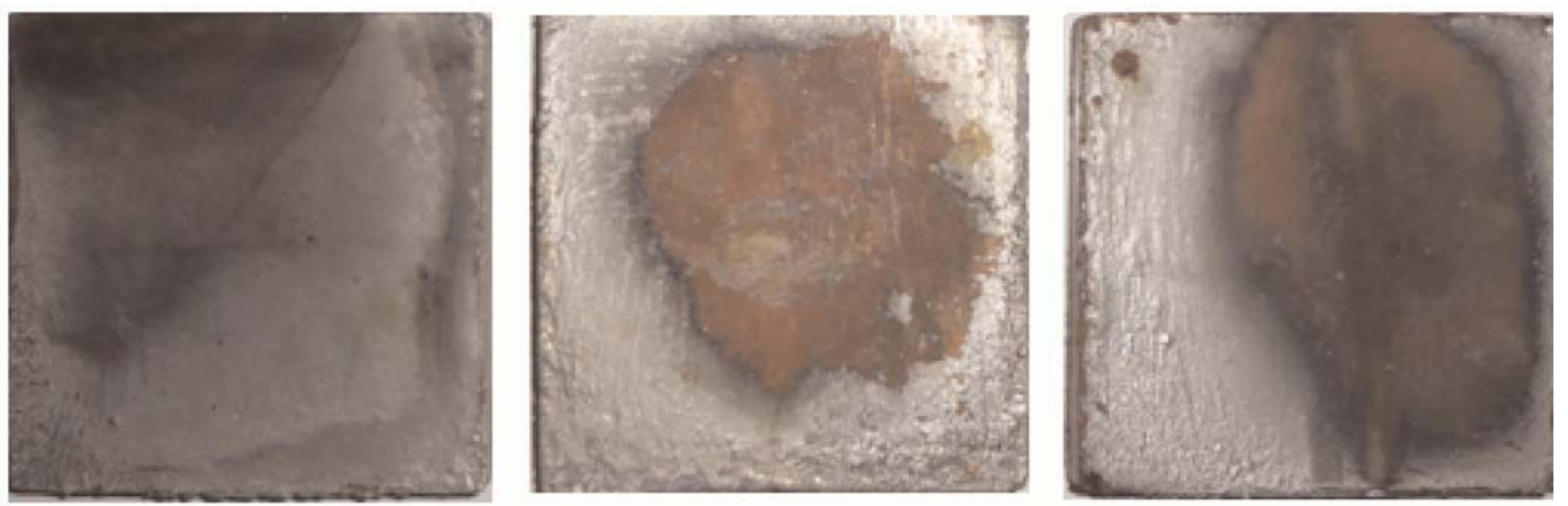

Fig. 14. Variation in electroplating parameters cause uneven plating 
According to (Mandich, 2002), the control of $\mathrm{pH}$ is also essential in order to assure good quality platings. The $\mathrm{pH}$ of nickel plating bath should be maintained between 3.5 and 4.5. A $\mathrm{pH}<3.0$ promotes the decrease in bright throwing power and $\mathrm{pH}>4.5$ leads to the formation of insoluble basic iron compounds, when electroplating is carried on metal and non-metal surfaces and can produce dark plates since the basic nickel salts will plate out. A pH of 5.0 was observed in the bath and that could have produced an uneven plating (Fig. 14). Since the samples were transferred from one solution to another, pollution of electrolyte was also observed. Due to the pollution, the electrolyte looses it properties and causes decrease in coating thickness.

Later, with the identification of the problems the ideal solution was prepared as discussed in the previous literature. The $\mathrm{pH}$ and the temperature were properly maintained. The bonding of the successive layers was governed by oxidation of the deposited layers; hence the copper which is prone to oxidation was immediately coated with a layer of nickel.

Electroplating not only improves the aesthetics but also changes the chemical and mechanical properties of the work piece. The deposition of the nickel layer improves the corrosion resistance. The electroplating acts as a shield against electromagnetic radiations and has the capability to block UV radiations which can cause degradation of plastics.

Electroplated samples were also subjected to water absorption tests, wherein the samples are dipped in water for a period of 24 hours at a maintained temperature of $23^{\circ} \mathrm{C}$. For the water absorption test, the specimens were dried in an oven for a specified time and temperature and then placed in a desiccator to cool. Immediately upon cooling, the specimens were weighed. The material was then immersed in water at agreed upon conditions, often $23^{\circ} \mathrm{C}$ for 24 hours or until equilibrium. Specimens were removed, patted dry with a lint free cloth, and weighed. The testing was conducted as per ASTM D570. It was observed that the electroplated samples had absorbed less water in comparison with the non coated polyamide specimens. The initial weight of the electroplated samples was $21.908 \mathrm{gm}$ and the samples after water absorption were $21.909 \mathrm{gm}$ i.e., the electroplated samples had absorbed $0.00456 \%$ of water. The initial weight of uncoated samples was $16.505 \mathrm{gm}$ and after subjecting them for water absorption tests the weight of the samples was $16.609 \mathrm{gm}$. i.e., the non coated samples had absorbed $0.63 \%$ of water. This indicates that absorption rate of electroplated samples is very much less in comparison with non coated samples, thus making them usable in application like sanitary items like water taps, showers, toilet showers, etc.

\section{Conclusion}

Copper based conductive paint was coated onto PA6/ Nylon6 plastic to create $\mathrm{Cu}$-seeded surfaces onto which $\mathrm{Cu}$ or Ni could be readily deposited through electroplating procedure, converting the non-conductive plastic surface into conductive. Simple tape test, electrical conductivity measurement, was carried out on PA6 specimens before and after electroplating deposition. Two types of PA6 samples were prepared scoured and unscoured of which unscoured samples offered least resistance to peeling due to the smooth surface of PA6 samples. The electroplating procedure developed in this study may open up a new route of deposition on plastics (POP) for printed circuit boards, electromagnetic interference shielding, and many other applications where ABS plastics are currently being used.

\section{References}

ASTM. (2003), In B374-96 (2003) Standard Terminology Relating to Electroplating. ASTM International: West Conshohocken, PA.

Baudrand (1994), Electroless nickel plating, surface engineering (Vol. 5). ASM Hand Book, Material Park, Ohio: American Society for Materials.

Dohrman P (n.d.). Demand Media, Inc. Retrieved from eHow: http://www.ehow.com/how_6168466_electroplate-plastic.html

Hart RP (1995), Electroplating of plastics. Nickel Development institute, Technical series No 10078. 1-9.

Helen H and Lou Y H (2006), Electroplating, Encyclopedia of Chemical Processing. Taylor \& Francis. 
Kanani N (2004), Electroplating: Basic Principles, Processes and Practice. U.K: Elsevier Advanced Technology: Oxford.

Mandich HG (2002), Understanding and troubleshooting decorative nickel electroplating systems-part I: Introduction and brightness problems. Metal Finishing. 100 (2): 83-91.

Parkinson R (1994), Plating on Plastics - An Industry Review. Plating \& Surface Finishing. 81: 32-35.
Roy Bjorlin WC (2004, 05 18). Conductive Painting of Plastics: Delivering Value and Flexibility. Retrieved from Interference technology, Media: http://www. interferencetechnology.com/conductive-painting-ofplastics-delivering-value-and-flexibility/

Received:11 October 2012; Revised: 08 July 2013; Accepted: 18 July 2013. 